\title{
Development of an interaction model of sea and land transport in the transportation of perishable goods
}

\author{
Vera Baginova ${ }^{1 *}$, Dmitry Ushakov ${ }^{1}$, and Andrey Zenkin ${ }^{1}$ \\ ${ }^{1}$ Russian University of Transport (Moscow Institute of Transport Engineers (RUT - MIIT), \\ Obrazcova St., 9b9, Moscow, 127994, Russia
}

\begin{abstract}
The issues of the interaction of sea and land transport during the transportation of perishable goods are especially in demand at present in connection with the active development of intermodal transport. In addition, due to the rapidly changing specifics of the transport and logistics infrastructure in ports and terminals, the organization of transportation of perishable goods, which are especially vulnerable in terms of quality, requires new approaches and methods. The paper notes the high importance of preliminary preparation for the process of interaction between marine and land transport by operators of marine and land transport. On the part of the marine transport operator, it is advisable to focus on the pre-contractual work and clarification of the conditions for the formation of the freight rate; on the part of the land transportation operator, in the process of preliminary preparation, the state of the transport network for transporting refrigerated cargo near the port is of great importance. The paper proposes two new indicators for assessing the state of the transport network for the transportation of refrigerated goods. At the end of the paper, a model of the interaction of sea and land transport during the transportation of perishable goods with the expression of the multitude of cargo flows of perishable goods in the port through the matrix form is presented.
\end{abstract}

\section{Introduction}

Improving the interaction of marine and land transport operators in the field of transportations of perishable goods in ports can have a significant impact on the quality and affordability of transport and logistics schemes for the delivery of food cargo passing through certain transport hubs, on the socio-economic development of the region as a whole [1-6].

As an object of consideration, it seems advisable to choose a refrigerated container vehicle, which is currently the most high-tech and popular type of refrigerated transport equipment. The formalization of measures to improve the interaction of marine and land transport in the port is proposed to be divided into three stages:

${ }^{*}$ Corresponding author: vvbaginova@gmail.com 
- a preliminary stage from the side of the marine transport operator with intermodal refrigerated container traffic (Ps);

- a preliminary stage from the side of the land transport operator with intermodal refrigerated container traffic $(\mathrm{Pl})$;

- procedures and operations carried out with the refrigerator container and with the cargo transported by it in the port (Pp) [7-10].

\section{Results}

The task of choosing a set of solutions for optimal solutions for managing the effective interaction of marine and land transport in the port I opt consists of those stages and can be expressed through the objective function:

$$
\mathrm{I} \text { opt }=\{\mathrm{Ps}, \mathrm{Pl}, \mathrm{Pp}\}
$$

The preliminary stage on the part of the marine transport operator with intermodal refrigerated container traffic includes, first of all, a detailed study of the draft terms of the contract for the transportation of the refrigerated container with cargo, determination of the freight rate and its components.

The freight rate is the cost of transporting a unit of cargo by marine transport, in our case, the cost of transporting one refrigerated container (for example, a 40-foot container). The principle of freight rate formation is as follows. The base or "ocean" freight rate is determined, and then various freight surcharges are added to it, which form the final delivery price. In addition, the terms of use of this freight rate are also specified in the contract of carriage by marine transport, indicating the places of transfer of the container from the consignor of the shipping company to the port of departure and from the shipping company to the consignee at the port of destination; distribution of responsibility for the payment of all links of container transportation and handling operations between the shipping company and the cargo owner.

For the owner of perishable cargo, in order to minimize the threat of damage to the quality of the cargo and minimize the processing time of the refrigerator container, the priority is when the shipping company assumes the responsibility of ensuring delivery by road at the port of departure and port of destination, as well as appropriate loading and unloading operations [11-13]. be

Those, freight rate optimally adapted to optimize the interaction processes (f opt) will

$$
\text { fopt }=\{\text { Fauto O, Lo, Fsea, Ld, Fauto D }\} \text {, where }
$$

Fauto $\mathrm{O}$ - auto delivery of a refrigerated container at the port of departure;

Lo - loading the refrigerated container on board the vessel at the port of departure;

Fsea - transportation of a refrigerated container to a ship by marine transport;

Ld - unloading a refrigerated container from a ship at the port of destination;

Fauto D - auto delivery of a refrigerated container at the port of destination.

Another important aspect of the stage of preparation for the process of interaction between marine and land transport during the movement of refrigerated containers by marine transport to the port from the sea is the speed of returning an empty refrigerated container after unloading at the terminal of a shipping company. Refrigerated container shipments are often currently carried out in bills of lading in quantities of a few at regular intervals. Perishable goods must arrive at a warehouse in the sales region evenly. After all the clearance procedures at the container in port, the consignee can reload the cargo to another container delivered in advance, or deliver the container to the shipping company to its own warehouse, unload and deliver it to the terminal of the shipping company or port. A situation arises when several refrigerated containers with cargo of a certain cargo owner are handled at the port when switching to land transport, and several containers of the same 
cargo owner are already unloaded at warehouses at a considerable distance from the port and after unloading these containers must be returned either to the port or to the shipping terminal inside the territory of the country of destination.

Shipping companies, as a rule, determine for the cargo owner 3-5 days of using the container free of charge after unloading from the vessel. In case of non-return during the grace period, fines are imposed on the cargo owner. If the container was not returned on time by the shipping company without leaving the port, then the penalty is called "demurrage", if the container was not returned on time when removed from the port, the penalty is called "detention". These fines can reach significant values, and with an increase in the time of non-return of demurrage and detention, they grow significantly. So if, in the first ten days, the fine can be 10-15 am. dollars a day for one container, then in the second ten days it's already 80-100 am. dollars a day for one container. Of course, in the case of the container being transported by the shipping company from the port, the consignee should unload the container as soon as possible after unloading the container at its warehouse in the interior of the country. The number and location of container terminals of various shipping companies in the territories of different countries have their own characteristics. In order to minimize the occurrence of a situation when a detention is presented with a shipping company, the cargo owner must choose a shipping company, one of the terminals of which is located in the immediate vicinity of the consignee's warehouse.

Thus:

$$
\text { as } \mathrm{S} \rightarrow \min , \mathrm{D} \rightarrow 0 \text {, where }
$$

$\mathrm{S}$ - distance from the consignee's warehouse to the terminal of the shipping company;

$\mathrm{D}$ is the value of detention.

The preliminary stage on the part of the land transport operator during intermodal refrigerated container traffic $(\mathrm{Pl})$ includes, first of all, an assessment of the state of the regional transport network near the port (Figure 1). The higher the level of technological equipment of individual network elements, the more coordinated the operation of refrigerated containers, the better and faster cargo owners will be able to process refrigerated containers [3].

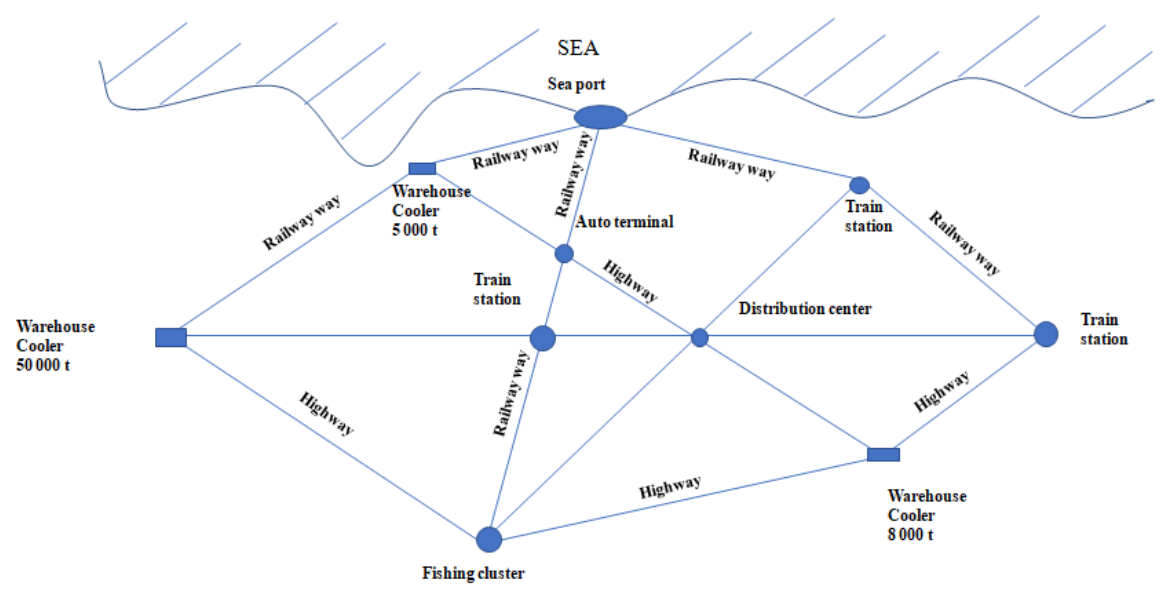

Fig. 1. Schematic illustration of a transport network for transporting refrigerated cargo near a major port.

To assess the degree of network development, there is the Morlock indicator:

$$
\mathrm{I} \mathrm{m}=\sum_{a b \in \mathrm{P}}^{n} l^{a b} / \sum_{a b \in \mathrm{P}}^{n} l^{* a b}
$$


where $\boldsymbol{l}^{a b}$ - the length of the shortest path in the network from a to b,

$\boldsymbol{l}^{* \boldsymbol{a} \boldsymbol{b}}$ - the distance from a to $\mathrm{b}$ in a straight line.

And also the Kansky indicator:

$$
\beta=\mathrm{n} \mathrm{L} / \mathrm{n} \mathrm{N} \text {, where }
$$

$\mathrm{n} \mathrm{L}$ - the number of arcs,

$\mathrm{n} \mathrm{N}$ - the number of nodes [3].

In this paper, for a more complete assessment of the state and dynamics of the development of the network for the transportation of refrigerated goods, it is proposed to introduce two additional indicators: an indicator of the level of intermodality $(\Theta)$ and an indicator of the level of use of the network by transportation of perishable goods $(\varphi)$.

$$
\Theta=\mathrm{Vt} / \mathrm{V} \text { int, where }
$$
tons),

$\mathrm{V} \mathrm{t}$ - the total volume of traffic on the network for a certain period of time (thousand

$\mathrm{V}$ int - the volume of intermodal transport over the network for a certain period of time (thousand tons).

$$
\varphi=\mathrm{Vt} / \mathrm{V} \text { ref, where }
$$

$\mathrm{V} \mathrm{t}$ - the total volume of traffic on the network for a certain period of time (thousand tons),

V ref - volume of transportation of perishable goods over the network for a certain period of time (thousand tons).

After completion of the preparatory measures by the operator of marine and land transport, it is advisable to agree on the number of bills of lading for a certain period of time and the number of refrigerated containers in each bills of lading based on the information received in the preliminary stage.

The procedures and operations carried out with the refrigerator container and with the cargo transported by it in the port (Pp) can be represented in the form of a set:

$$
\mathrm{Pp}=\{\mathrm{E}, \mathrm{L}, \mathrm{Q}, \mathrm{R}, \mathrm{T}, \mathrm{C}\}
$$

$\mathrm{E}-$ set of mechanisms and devices in the port

$\mathrm{L}$ - set of technological operations in the port with the processed refrigerated container

Q - set of technological procedures aimed at checking the quality of the refrigerated container installation;

$\mathrm{R}$ - set of technological operations at the port railway station to the port with processed refrigerator container couplings;

$\mathrm{T}$ - set of refrigerated couplings processed at the railway station and in the port

$\mathrm{C}$ - set of perishable cargo flows handled in the port.

There are three options for handling refrigerated containers in a port:

- after unloading the refrigerator container from the vessel to the port berth and carrying out all necessary formalities, the container is transported to the perishable goods warehouse in the port territory and the cargo is unloaded from the container to the refrigerator 
warehouse in the port;

- after unloading the refrigerator container from the vessel to the port berth and carrying out all the necessary formalities, the container is transported to the port railway station, where cargo is transferred from the container of the shipping company to the container of the consignee;

- after unloading the refrigerator container from the vessel to the port berth and carrying out all necessary formalities, the container is transported to the consignee's warehouse in the interior of the consignee's country.

A lot of perishable cargo flows handled in the port can be represented through two matrices in which the columns correspond to the refrigerator container options, and the rows correspond to the directions of their movement between the container terminals in the port, the port railway station and the warehouse - refrigerator in the port.

$$
\begin{aligned}
& \text { CF ref }=\langle\text { Mref, Wref }\rangle
\end{aligned}
$$

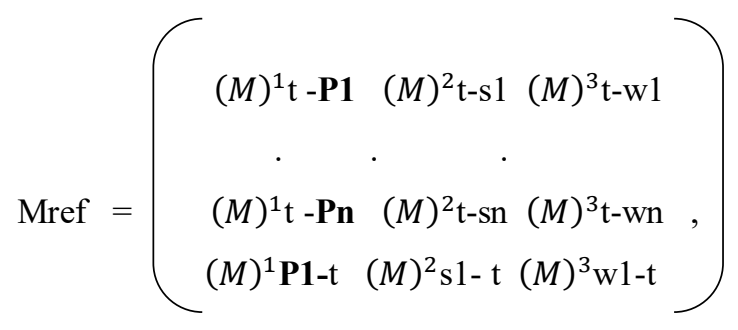

$$
\begin{aligned}
& (M)^{1} \text { Pn-t }(M)^{2} \text { sn -t }(M)^{3} \text { wn-t } \\
& \text { Wref }=\left(\begin{array}{ccc}
(W)^{1} \mathrm{t}-\mathbf{P 1} & (W)^{2} \mathrm{t}-\mathrm{s} 1 & (W)^{3} \mathrm{t}-\mathrm{w} 1 \\
\cdot & \cdot & \cdot \\
(W)^{1} \mathrm{t}-\mathbf{P n} & (W)^{2} \mathrm{t}-\mathrm{sn} & (W)^{3} \mathrm{t}-\mathrm{wn} \\
(W)^{1} \mathbf{P 1} 1-\mathrm{t} & (W)^{2} \mathrm{~s} 1-\mathrm{t} & (W)^{3} \mathrm{w} 1-\mathrm{t}
\end{array}\right) \\
& (W)^{1} \text { Pn-t }(W)^{2} \text { sn -t }(W)^{3} \text { wn-t }
\end{aligned}
$$

where $(M)^{1} \mathrm{t}-\mathbf{P 1}, \ldots .,(M)^{1} \mathrm{t}-\mathbf{P n} \quad,(M)^{1} \mathbf{P} 1-\mathrm{t}, \ldots,(M)^{1} \mathbf{P n}-\mathrm{t} \quad$ и $(W)^{1} \mathrm{t}-\mathbf{P 1}$, $\ldots, \quad(W)^{1} \mathrm{t}-\mathbf{P n},(W)^{1} \mathbf{P 1}-\mathrm{t}, \ldots,(W)^{1} \mathbf{P n}-\mathrm{t} \quad$ - the number and gross weight of refrigerated containers from the port container terminal to the warehouse - refrigerator in the port and back; $(M)^{2} \mathrm{t}-\mathrm{s} 1, \ldots,(M)^{2} \mathrm{t}-\mathrm{sn},(M)^{2} \mathrm{~s} 1-\mathrm{t}, \ldots,(M)^{2} \mathrm{sn}-\mathrm{t} \quad,(W)^{2} \mathrm{t}-\mathrm{s} 1, \ldots$, $(W)^{2} \mathrm{t}$-sn $,(W)^{2} \mathrm{~s} 1-\mathrm{t}, \ldots,(W)^{2} \mathrm{sn}-\mathrm{t}$ - the number and gross weight of refrigerated containers from the container terminal of the port to the railway station and back; $(M)^{3} \mathrm{t}-\mathrm{w} 1$ $, \ldots,(M)^{3} \mathrm{t}$-wn , $(M)^{3} \mathrm{w} 1-\mathrm{t}, \ldots,(M)^{3}$ wn-t $,(W)^{3} \mathrm{t}-\mathrm{w} 1, \ldots,(W)^{3} \mathrm{t}-\mathrm{wn}, \ldots,(W)^{3} \mathrm{w} 1-\mathrm{t}$ $, \ldots, \quad(W)^{3} \mathrm{wn}-\mathrm{t}$ - the number and gross weight of refrigerated containers from the container terminal of the port to the consignee's warehouse in the interior of the country 
and back [2].

\section{Conclusions}

Summarizing the foregoing, the model of the interaction of marine and land transport in the transportation of perishable goods can be represented in the form of a scheme shown in Figure 2.

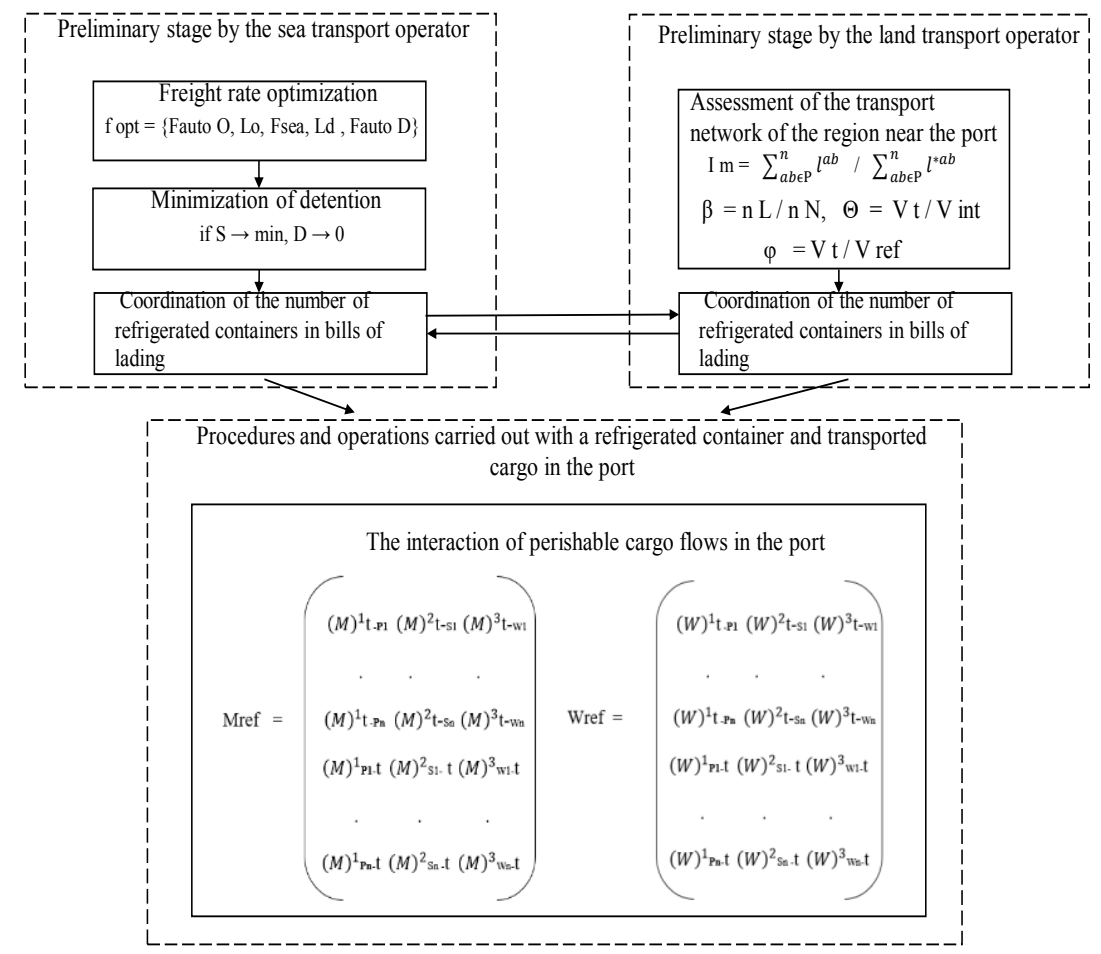

Fig. 2. The model of the interaction of marine and land transport in the transportation of perishable goods

The importance of the preliminary stages on the part of the operators of marine land transport is due to the constantly changing situation in the port and the neighboring region, associated with seasonal differences in the intensity of cargo flows of all perishable goods. The proposed model allows, on the one hand to reduce the transit time of perishable cargo of the seaport during the intermodal delivery scheme, and on the other hand to minimize transport costs associated primarily with the operation of refrigerated containers.

Comparing the efficiency of exporting refrigerated containers from the port by road and rail transport, attention should be paid to the peculiarities of the technology for exporting refrigerated containers from the port by different modes of transport. To send refrigerated containers by rail transport, it is necessary to carry out such technological operations as: feeding electrified fitting platforms, forming an empty refrigerated container coupler, loading refrigerated containers onto the coupler platforms, sending the coupler. For shipping refrigerated containers by road transport, the set of procedures is greatly simplified: the refrigerated container is loaded onto a container platform truck and the car is sent. 


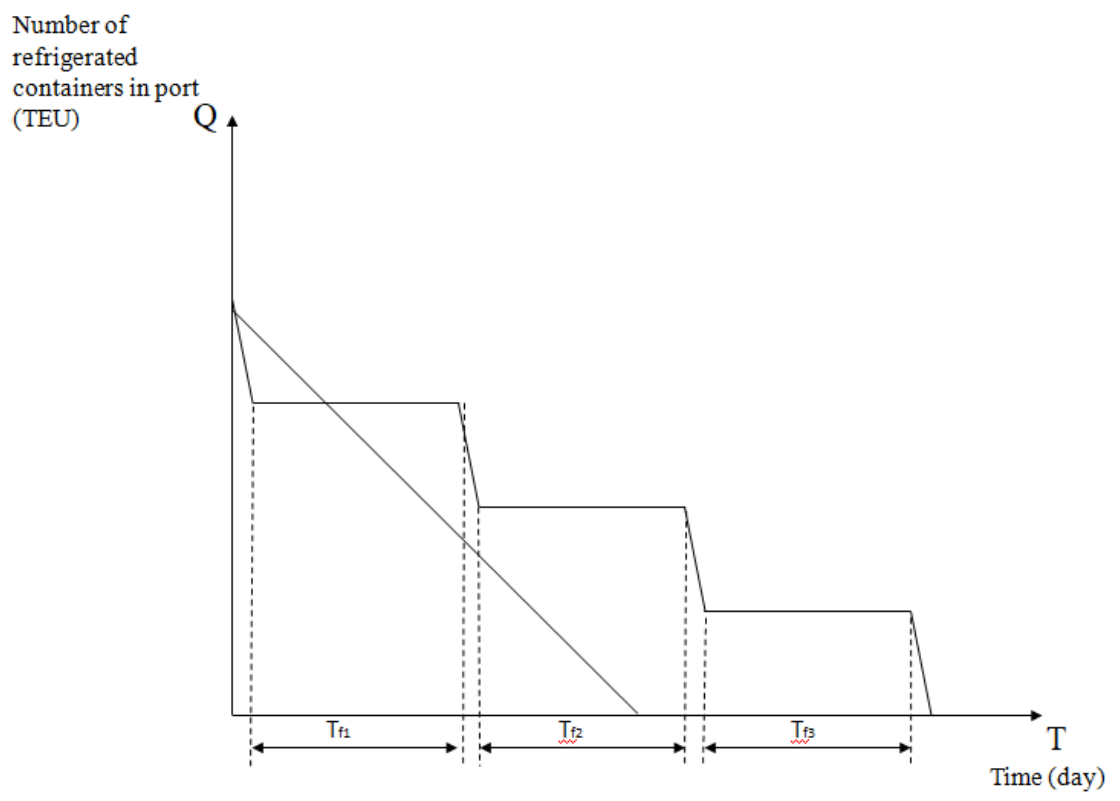

Fig. 3. A graph comparing the dynamics of the export of refrigerated containers from the port by road and rail transport, where

Q - the number of refrigerated containers at the port for export (TEU),

$\mathrm{T}$ - time (day),

$\mathrm{T}_{\text {truck }}$ - the time of transportation of refrigerated containers from the port by road transport (days),

$\mathrm{T}_{\text {rail }}$ - time of exporting refrigerated containers from the port by rail transport (days),

We can say that the nature of the shipment flow from the port of refrigerator containers by rail transport is a classic discrete character:

$$
\mathrm{P}=\sum_{i=1}^{n} P i
$$

at the same time, the nature of the shipment flow from the port of refrigerated containers by road transport is approaching continuous.

$$
\mathrm{P}=\sum_{i=1}^{n} P i \longrightarrow \mathrm{P}=\int_{t 1}^{t 2} f(t) d t
$$

where

$t 1$ - start time of the export of a batch of refrigerated containers from the port,

$\mathrm{t} 2$ - time of the end of the export of a batch of refrigerated containers from the port.

A graph comparing the dynamics of the export of refrigerated containers from the port by road and rail transport is presented in Figure 2.

Thus, based on the foregoing, we can conclude that when using the model of interaction between marine and land transport during the transportation of perishable goods, one should be guided by the characteristics of the delivered batches of refrigerated containers, their sizes and frequency of delivery [8].

\section{References}

1. V. Baginova, S. Lyovin, D. Ushakov, E3S Web of Conferences, 08058 (2019). 
2. V.A. Anisimov, M.V. Nechiporuk, Bulletin of the St. Petersburg University of Railway Transport 3(40), 9-15 (2014)

3. V.V. Baginova, D.V. Ushakov, Economics of railways, 11, 45-51 (2019)

4. V.V. Baginova, D.V. Ushakov, Science and technology of transport, 3, 30-33 (2019)

5. V.V. Baginova, D.V. Ushakov, Bulletin of transport information, 3, 30-33 (2019)

6. D.V. Ushakov, N.I. Gladyshev, Marine fleet, 7/8, 28-30 (1993)

7. V. Vorobyov, A. Manakov, I. Yanshina, I. Repina, Advances in Intelligent Systems and Computing, Vol. 1116 (2020). DOI: 10.1007/978-3-030-37919-3_69

8. V. Vorobyov, A. Manakov, A. Reger, I. Tanaino, MATEC Web of Conferences 216, 02009 (2018). DOI: 10.1051/matecconf/201821602009

9. A. Manakov, A. Abramov, A. Ilinykh, V. Aksenov, MATEC Web of Conferences 239, 04001 (2018). DOI: 10.1051/matecconf/201823904001.

10. D.V. Ushakov, Refrigeration business, 7, 14-18, (2010).

11. D.V. Ushakov, Motor transport company, 8, 23-25 (2015).

12. D.V. Ushakov, Logistics and supply chain management, 2(79), 82-86 (2017).

13. D.V. Ushakov, World of Transport, 5(66), 72-77 (2016) 